\title{
Travesti não entra: uma análise crítica sobre o tratamento dado as travestis durante a ditadura civil-militar
}

Transvestites do not enter: a critical analysis of the treatment given to transvestites during the Military Civil Dictatorship

\author{
Hiago de Souza Tavares \\ hiagotavares@id.uff.br \\ Pedagogo (Isepam), licenciado em ciências \\ sociais (IFF-Campos), estudante de psicologia \\ (UFF Campos), pós graduado em docência no \\ século XXI ( IFF-Campos) e participante do \\ Nugedis: Núcleo de Gênero, Diversidade e \\ Sexualidade do IFF- Campos.

\section{Marwyn Soares de Souza marwynsouza@hotmail.com} \\ Bacharel em Psicologia Pela Universidade \\ Estácio De Sá (UNESA); Especialista Em \\ Psicopedagogia Pela Faculdade Estratego \\ (ESTRATEGO); Pós-Graduando Psicologia \\ Existencial Humanista E Fenomenológica \\ (FAVENI).
}

\section{Resumo}

O principal objetivo deste artigo é expor o período da ditatura militar brasileira e o cenário de perseguição, opressão e violências acometidas a pessoas travestis e homossexuais; analisar as vivências registradas daquela época, a partir dos jornais; e, de modo interseccional, refletir sobre sociedade e a política de censura e repressão dos corpos desviantes.

Palavras-chave: Travestilidade; Violências de Gênero, Discriminação Interseccional.

\begin{abstract}
The main objective of this article is to expose the period of the Brazilian military dictatorship and the scenario of persecution, oppression, and violence against transvestite and homosexual people. Analyze the experiences recorded at that time, from the newspapers, and in an intersectional way, reflect on society and the policies of censorship and repression of deviant bodies.
\end{abstract}

Keywords: Transvestility; Gender-based violence; Intersectional Discrimination. 
TAVARES, Hiago de Souza; SOUZA, Marwyn Soares de. Travesti não entra: Uma análise crítica sobre o tratamento dado as travestis durante a Ditadura Civil Militar.

\section{Introdução}

A ditadura civil-militar no Brasil ou "quinta” República Brasileira foi o nome designado ao regime e período instaurado entre $1^{\circ}$ de abril de 1964 até 15 de março de 1985, sob comando repressivo e ostensivo do governo militar e de seus representantes. Durante esse período de extremismo e censura, o governo brasileiro manteve os olhos fechados para uma parte da população. De acordo com Silva e Brito (2017), foi um período de muita violência, opressão, prisões e mortes. Pessoas homossexuais ${ }^{1}$ e travestis eram perseguidas, como também as pessoas pretas, indígenas, alguns artistas e políticos.

Este artigo busca apresentar um percurso histórico sobre como as pessoas travestis foram afetadas pela ditadura civil-militar e como a mídia, mais especificamente os jornais da época, tratavam essas vivências. A metodologia, a pesquisa histórica do jornal Diário de Notícias durante o Ato Institucional número 5, na incursão de uma análise histórica crítica sobre as temáticas envolvidas. Durante a "pesquisa-ação", as leituras e os fichamentos documentais foram de encontro às narrativas jornalísticas, propiciando uma visão analítica dos dados historicizados. Akotirene (2019) e Oliveira (2020) vão descrever a “interseccionalidade” como uma analítica que compreende e promove aproximações possíveis de realidade vivenciada por muitas pessoas e, ao mesmo tempo, legitimar que as dores e as pessoas são singulares, e as vivências e as subjetividades específicas como "raça", classe e gênero carregam marcas coletivas mesmo sendo experiências únicas. Silva e Brito (2017) acrescentam que faltam estudos sobre a repressão de pessoas travestis na época da ditadura militar. Não é difícil encontrar nas bibliotecas e em acervos on-line informações sobre o período do golpe de 1964 e seu decorrer. Há análises políticas, econômicas e até da censura de forma geral, mas quando se trata da violência sofrida pelo público travesti, é raro pesquisas sobre o tema. Os principais estudos sobre a violência com pessoas travestis na ditadura foram escritos por James Green e Renan Quinalha (2014). Ambos apontam que “o tema das sexualidades é abordado ignorandose sua relativa autonomia dos processos políticos mais gerais ou, em sentido oposto, ele é discutido como se estivesse completamente desconectado da história do período" (Green; Quinalha, 2014, p.19).

\footnotetext{
${ }^{1}$ Consideramos pessoas homossexuais aquelas que sentem atração sexual-afetiva por sujeitos do mesmo gênero ou sexo biológico.

2 Pesquisa-ação é "um tipo de pesquisa de ação, uma pesquisa comparativa acerca das condições e resultados de diversas formas de ação social e pesquisa que leva à ação social" proposta por Kurt Lewin. Melo, Armando Sérgio Emerenciano de, Maia, Osterne Nonato e Chaves, Hamilton VianaLewin e a pesquisa-ação: gênese, aplicação e finalidade. Fractal : Revista de Psicologia [on-line]. 2016, v. 28, n. 1 [Acesso em: 12 set 2021] , p. 153-159. Disponível em: <https://doi.org/10.1590/1984-0292/1162>. ISSN 1984-0292. https://doi.org/10.1590/1984-0292/1162.
} 
TAVARES, Hiago de Souza; SOUZA, Marwyn Soares de. Travesti não entra: Uma análise crítica sobre o tratamento dado as travestis durante a Ditadura Civil Militar.

Tal desconexão ocorre por um apagamento histórico das sexualidades ditas desviantes, que fogem da norma. Com isso, na obra intitulada Homossexualidades, Repressão e Resistência em Tempos de Ditadura Militar no Brasil (Green; Quinalha, 2014), os autores apontam que a criação das Comissões da Verdade - como reparação histórica - foi essencial para colocar o assunto das sexualidades não como assunto transversal, mas com um recorte da população que sofreu perseguição, principalmente na criação do AI-5. A comissão, como apontam Green e Quinalha (2014), investigou a violação dos Direitos Humanos.

A primeira investigação obteve o nome de "Ditadura e Homossexualidade: a resistência do Movimento LGBT" e foi realizada em 26 de novembro de 2013. A segunda ocorreu em 29 de março de 2014 com a parceria do Memorial da Resistência. As duas audiências geraram o livro descrito acima, em que os autores recriam a luta das travestis pela sobrevivência da sua vida e identidade no período ditatorial, além de sua contextualização com as questões políticas do seu tempo.

\title{
Histórico das perseguições
}

É importante começar a descrição alegando que, por mais que o período histórico se baseie no período militar, principalmente no período Médici³ ${ }^{3}$ (1969-1974), precisa-se acrescentar que

\begin{abstract}
Desde a Guerra Fria, os discursos médicos e policiais, tentavam patologizar e controlar a homossexualidade, vista como uma prática perigosa, secreta, degenerativa, e ligada ao gênero; uma prática que estas autoridades associaram, imprecisamente, com a subversão e a (in)segurança nacional. (Green; Quinalha, 2014, p.30)
\end{abstract}

Em uma época marcada pelo anticomunismo -anos 1960 a 1970 - como apontam Green e Quinalha (2014), qualquer pessoa que desviasse da moral e norma estabelecida era tido como subversivo e, se fugiam dos valores conservadores, mereciam ser simplesmente aniquilados do convívio social. Na polícia, por exemplo, havia nas fichas "alegações de homossexual” como acusação às pessoas.

Segundo Tavares (2018), e a mídia também, principalmente os jornais, como analisaremos mais à frente, alegam um clima de caça às travestis e homossexuais. Em um momento em que não era necessário provas para haver prisões, nem habeas corpus, era notório

\footnotetext{
${ }^{3}$ Emílio Garrastazu Médici foi o 28ำ Presidente do Brasil, o terceiro do período da ditadura militar brasileira, entre 30 de outubro de 1969 e 15 de março de 1974.
} 
TAVARES, Hiago de Souza; SOUZA, Marwyn Soares de. Travesti não entra: Uma análise crítica sobre o tratamento dado as travestis durante a Ditadura Civil Militar.

o abuso da polícia com tais pessoas A "Operação Tarântula"4, por exemplo, prendeu travestis e pessoas (Quinalha, 2017) com sexualidades ditas desviantes com tanta frequência que os autores apontam que, em uma só noite, 300 pessoas podiam ser levadas até a polícia. Agentes patrulhavam as ruas em busca dos que eles chamavam de "vadios", termo que era dado às pessoas sem trabalho fixo, às quais as travestis eram associadas. Qualquer reunião ou encontro de LGBT's ou mulheres eram rapidamente dispersados através da força. Essa operação limpeza consistia em

Constantes realizações de blitz noturnas, batidas policiais, que monitoram e muitas vezes fechavam pontos de sociabilidade desses segmentos sociais. Esse plano de moralização e de combate aos inferninhos visava a detenção dos "homens de batom e pó de arroz" e acabar com o trottoir, como forma de sanear o espaço urbano e convivência social. (Green; Quinalha, 2014, p.79).

A censura também controlou os eventos da população LGBTQ+. Por mais que artistas como Rogéria e Ney Matogrosso tivessem sua arte respeitada no período ditatorial, a maioria dos artistas que não se enquadram em padrões heteronormativos eram caçados. Tais atos, como apontam Green e Quinalha (2014), teriam como principal característica a limpeza do espaço urbano. Tanto que foi criada a Operação Cidade, em que rondas de policiais ministradas pelo delegado José Wilson Richetti, apoiadas pelo jornal O Estado de São Paulo, colocavam ainda mais as travestis em um gueto de vulnerabilidade e coerção. Assim, pessoas travestis, consideradas "desviantes", passaram a sofrer perseguições violentas, com marcas de brutalidade física, na maioria dos casos. Esses sujeitos também sofriam o acréscimo de estigmas sociais, das chamadas violências e "discriminação interseccional", pois pessoas pretas (ou de pele escura) que performavam-se à travestilidade ou à homossexualidade eram abordadas com muito mais violência, se comparadas a pessoas brancas travestis e/ou homossexuais no Brasil. Com isso,

A discriminação interseccional é particularmente difícil de ser identificada em contextos onde forças econômicas, culturais e sociais silenciosamente moldam o pano de fundo, de forma a colocar as mulheres (e outros seres humanos) em uma posição onde acabam sendo afetadas por outros sistemas de subordinação. Por ser tão comum, a ponto de parecer um fato da vida, natural ou pelo menos imutável, esse pano de fundo (estrutural) é, muitas vezes, invisível. O efeito disso é que somente o aspecto mais imediato da discriminação é percebido, enquanto que a estrutura que coloca as mulheres na posição de "receber" tal subordinação permanece obscurecida. (Crenshaw, 2002, p. 176 apud Oliveira, 2020, p. 80 - grifo nosso)

\footnotetext{
${ }^{4}$ Foi a perseguição para com pessoas LGBT durante os anos 1970 a 1980, como uma espécie de "caça" às travestis.
} 
O Brasil viveu e continua vivendo violências que violam os direitos humanos relacionado a gênero, etnias, classe e as leituras e as análises das fontes e dados devem levar em consideração os atravessamentos e afetações para evitar tornar-se uma analítica que "falte": falte analisar a relação de gênero com étnica, ou com classe, acessibilidade. É necessário que os futuros pesquisadores e pesquisadoras fiquem atentos as essas interfases. Contudo, também concordo com a provocações de Oliveira (2020) sobre as abordagens "super inclusivas" tornarem-se uma forma de "remediar a condição ou abuso em questão tendem a ser tão anêmico quanto é a compreensão na qual se apoia a intervenção" (OLIVEIRA, p.80, 2020), logo é necessária uma escrita observacional crítica sobre os fenômenos analisados.

\section{Travestis e a mídia impressa: uma análise crítica do jornal de notícias}

A pesquisa foi realizada através do jornal Diário de Notícias, pelo fato ser uma mídia popular à época. Toda análise foi feita virtualmente na Biblioteca Nacional Digital. Após digitar a palavra travesti, na aba de pesquisa do site, na área da hemeroteca digital, apareceram 326 páginas correspondentes à palavra pesquisada. O período de busca correspondeu entre 1969 até 1973, quando houve intensificação da violência contra a população, no geral, e especificamente ao público LGBT, através do Ato Institucional número 5. O fragmento da pesquisa consiste em 26 notícias retiradas do Diário de Notícias, sendo as julgadas mais importantes citadas. A primeira notícia retirada do jornal tem o título: "Travesti não entra", a data de publicação corresponde a 20 de janeiro de 1970. A notícia, em suma, destaca a seguinte fala: "Informam a esta colunista que não serão aceitas inscrições de fantasias que tenham pinta de travesti” (Rizzo, 1970).

Em um outro fragmento, analisa-se o jornal do dia 30 de janeiro de 1970. Em meio a várias notícias aleatórias, aparece o seguinte título: "São cinquenta bonecas e vieram para sambar". Era muito associado o termo boneca com as travestis, na época, por causa das maquiagens exageradas que usavam. Na matéria, chama atenção o seguinte trecho:

O movimento de ontem no Galeão teve seu lance pitoresco ainda pela manhã quando desembarcaram de um avião 101 passageiros: eram do Internacional Namads Club - 40 mulheres e 50 bonecas que chegavam para possuir o carnaval do Rio (...) Um destes vinha na companhia da loura Suzanne. Ao perguntarem se era mulher, respondeu simplesmente: "Que importância tem isso?" A pergunta havia sido feita porque Alfredo Vidal informava que dois rapazes vinham em companhia de suas mulheres. A verdade é que não foi 
possível identificar, no duro, quem eram as esposas, quem eram os maridos. (Silveira, 1970, p.2)

O termo bonecas aparece com teor cômico na notícia, há a separação entre mulheres e bonecas. Essa separação é presente em várias situações sociais em que a segregação é presente. Como aponta Butler (2003), a sociedade qualifica humanidades, e sendo assim, também as desqualifica. Ou seja, há uma hierarquia de valores para cada indivíduo. Algumas pessoas seriam mais humanas do que outras em se tratando de questões de visibilidade e direitos sociais. No mesmo trecho do jornal, há um subtítulo chamado "confusão", que registra que um artista ficou irritado porque os repórteres teriam associado sua imagem à do público descrito na citação anterior. Diz a notícia: "No mesmo avião, chegou o artista russo Joseph Peters, naturalizado norte-americano e que ficou zangado ao achar que os repórteres o confundiram com um dos integrantes do grupo de bonecas" (Silveira, 1970, p.2).

A dominação masculina descrita por Bourdieu (2002) é importante para compreender o pensamento de como os homens tendem a não querer ser associados a qualquer coisa que remeta ao gênero feminino. Seja em coisas simples, como cores (rosa), por exemplo, seja nessas situações em que o corpo visto é o de um homem que traz consigo aspectos físicos e de vestimentas do gênero oposto, o que causa toda essa repulsa.

A pesquisa avalia, ainda, a primeira seção de 5 de fevereiro de 1970 do jornal. Com o título "Extremos: Elas corrompem menores e eles vão de travesti no "trottoir", Gilvandro Gambarra, em sua resenha policial, escreve:

Coisas de extremos, entremeados de extrema pouca vergonha. Em São Paulo, umas tais mulheres foram presas por corrupção (...) Acusadas de corromperem, com o amor enganoso e precoce, uns tais menores de 18 anos. (...) Ali na Praça Onze, do que à primeira vista, lhes pareciam 3 mulheres no feio "exercício" de balançarem a bolsinha. (Gambarra, 1970a, p.3)

O termo trottoir se refere simplesmente à prática da prostituição. Com a leitura da obra de Gazelatto e Gardin (2016), percebe-se que termos como pouca vergonha, amor enganoso, feio exercício são adjetivos que carregam um discurso de ódio, que legitima, e até incentiva, práticas agressivas para com minorias. "Tais mulheres”, como dito na citação, acima mostra como há a manifestação de desqualificação das pessoas, quando inclusive recusa-se a usar os seus nomes. Ainda no decorrer da matéria - e em todo jornal-, o nome de nascimento das travestis foi colocado e acentuado nos textos jornalísticos do jornal Diário de Notícias, porém, com intuito de integridade da população travesti, optou-se por não colocá-los neste trabalho. 
TAVARES, Hiago de Souza; SOUZA, Marwyn Soares de. Travesti não entra: Uma análise crítica sobre o tratamento dado as travestis durante a Ditadura Civil Militar.

Ainda que diretamente não sejam feitos discursos de ódio ou de motivação homofóbica, o silêncio, junto à alegação de que alguns assuntos devem ser tratados apenas no convívio doméstico, se constituem uma forma negativa de tratamento ao público travesti. Baptista se refere a essa situação com a expressão-conceito "amolar facas". Em seu livro, Cidade dos Sábios, ele descreve:

O fio da faca que esquarteja, ou o tiro certeiro nos olhos, possui aliados. Agentes sem rostos que preparam o solo para esses sinistros atos. Sem cara ou personalidade, podem ser encontrados em discursos, textos, falas, modos de viver, modos de pensar que circulam entre famílias, jornalistas, prefeitos, artistas, padres, psicanalistas etc. Destituídos de aparente crueldade, tais aliados amolam a faca e enfraquecem a vítima, reduzindo-a a pobre coitado, cúmplice do ato, carente de cuidado, fraco e estranho a nós, estranho a uma condição humana plenamente viva. (Baptista, 1999, p.46)

Gazelatto e Gardin (2016), concordam em apontar que o discurso de ódio contra a população LGBT pode ser refletido em agressões físicas. Com isso, falas com conteúdo odioso podem ser internalizadas e induzir a violências em quem as houve. No trecho acima, o autor amola facas e descreve os episódios de agressões relacionadas ao público LGBT, que indicam a existência de uma cultura e sociedade difíceis, com repulsa e recusa dos que se afastam dos padrões heteronormativos ou que subvertem a lógica heterossexual - branco, masculino, cisgênero e provedor, os designados sujeitos "homens".

Seguindo com a análise documental, matéria datada de 18 de agosto de 1970, na capa do jornal, traz o seguinte título: “Travesti com a imagem de Aiko Tanaka”. Um dos trechos aponta

\begin{abstract}
Aiko Tanaka, travesti paulista, enganou um júri de TV e venceu um concurso na escolha da mais bela nisei. No final, era homem e foi desclassificada. (...) A bela japonesinha não passava de um vigarista japonês, residente em São Paulo, que se travestiu para ganhar os prêmios do concurso. (...) Um dos mais traumatizados do júri é o jornalista Sérgio Bittencourt, que cantou prosas e versos à beleza de Akiko. (...) O travesti deverá ser recambiado para o Rio, pois se encontra em São Paulo, para prestar os "devidos esclarecimentos" na $12^{a}$ DP. (Diário de Notícias, 1970, p.1)
\end{abstract}

No trecho descrito sobre o concurso de beleza em 1970, que elegia a nissei (japonesas nascidas fora do Japão) mais bonita, consegue-se notar como a vitória de uma travesti causou embaraço para o evento. A travesti foi chamada de vigarista e foi encaminhada para a polícia para depor, como se tivesse cometido um crime. Importante também ressaltar que o termo “devidos esclarecimentos” está entre aspas, na matéria, indicando que não se sabe o que pode ter acontecido no depoimento da travesti. Por fim, é necessário apontar que um dos júris do 
TAVARES, Hiago de Souza; SOUZA, Marwyn Soares de. Travesti não entra: Uma análise crítica sobre o tratamento dado as travestis durante a Ditadura Civil Militar.

concurso tenha ficado, como aponta o texto, traumatizado por ter achado uma travesti bonita e tê-la elogiado. O corpo da travesti, como aponta Benedetti (2008), é um corpo negado a todo momento, é excluído de qualquer fonte de apreciação, pelo menos falada, comentada para as pessoas. Se seus corpos são desejados, são sempre em segredo.

O jornal do dia 25 de agosto de 1970, em outra resenha policial de título, traz: "Tramou a expulsão da esposa do planeta para viver com aquilo”. O autor da matéria, Gambarra (1970), descreve o caso de um homem que assassina sua esposa para se relacionar com uma travesti. $\mathrm{O}$ autor escreve, no decorrer da descrição: “(...) Pois seu último caso é com uma, digo, com um... Digo, não sei de travesti, que é como chamam essa pouca vergonha de homem vestido de mulher" (Gambarra, 1970, p.18). Há a clara presença da amolação de facas comentada nas páginas anteriores. Termos como "aquilo" para descrever uma pessoa travesti e apontando-a como "pouca vergonha", desqualificando-a, demonstram a violência no texto do autor. Além disso, sua citação de "homem vestido de mulher" remete ao que Butler (2003) aponta sobre existirem papéis de gênero e, também, como se portar socialmente. A vestimenta faz parte aqui de uma violação, de uma transgressão do gênero - como se houvesse caminhos inatos já para determinadas pessoas.

Com o título "A Travesti vai sair de cena", de 11 de janeiro de 1971, o tex to informa que: “Os espetáculos de travesti como o Les Girls, em cartaz há dois meses no teatro Miguel Lemos, estão destinados a desaparecer pois somente poderão exibir-se em boates, sendo expressamente vedada sua participação em shows públicos” (Domingues, 1971b, p.6). Há então, certos grupos que só são "aceitos" se continuarem nos seus guetos e sem voz pública ou legalidade para com a sociedade. Aqui, nota-se que travestis só eram permitidos como corpos a serem exibidos em boates e locais sexualizados e não em ambientes ditos públicos, onde a maioria das pessoas podia circular.

No jornal do dia 16 de junho de 1971, há a divulgação da morte de uma travesti chamada Ritinha, que "foi assassinada a tiros e navalhadas, ontem, sendo seu corpo encontrado perto de uma boca de fumo no campo de futebol a margem do Rio Mertil no Quilungo, em Vigário Geral” (Diário de Notícias, 1971, p.9). Na descrição dos fatos, cita-se que a travesti era "valente" e "dado a muitas brigas". Não se sabe se a travesti era mesmo violenta ou se apenas tentava reagir às agressões cometidas contra ela. Colocar a culpa na pessoa travesti é recorrente, na época, como apontam os fatos do jornal do dia 13 de julho de 1972, com o título: "Suicidase travesti surrado em hotel e suicidado no xadrez". Entre a escrita dos acontecimentos, a matéria aponta que a travesti "enforcou-se com a própria camisa (...) era dado a anormalidades 
TAVARES, Hiago de Souza; SOUZA, Marwyn Soares de. Travesti não entra: Uma análise crítica sobre o tratamento dado as travestis durante a Ditadura Civil Militar.

e costumava vestir-se como mulher na base do travesti" (Domingues, 1972a, p.8). A travesti foi surrada no hotel, pois o homem que estava com ela achou que fosse uma mulher cisgênera, porém a mãe da vítima alega que não houve enganação. Após ser presa (o rapaz que estava com ela não foi) e violentada várias vezes, como aponta o jornal, a travesti suicidou-se. No fim do texto, a mãe alega: “meu filho não era um criminoso. Criminosos são os que o espancaram no hotel".

Nota-se, nesse artigo do jornal, a culpa que carrega o ser travesti. Outras agressões e violação dos Direitos Humanos são presenciados na análise do jornal. Doze dias após o ocorrido acima, há outro acontecimento de agressão à população travesti. Com o título: "Travesti Valéria operado no nariz: soco fez fraturas". A matéria conta o fato da travesti ter levado um soco no rosto “em consequência da agressão de que foi vítima, na Glória, por parte do chofer do táxi em que viajava. Foi submetido a uma operação para redução e mobilização dos ossos nasais" (Domingues, 1972c, p.8).

Assim, o corpo travesti é visto com um objeto manipulável e a violência ocorre com a negação da vítima. Nesse sentido, é que a interseccionalidade, como apresenta Oliveira, é um conceito que “(...) analisa as estruturas sociais, as representações simbólicas e as subjetividades que, naturalizadas, produzem e reproduzem as desigualdades de gênero, orientação sexual e raça no sistema educacional" (Oliveira, 2020, p.90) como também em toda a estruturação da sociedade. Existem então, corpos que, perante a sociedade, não possuem a capacidade de escolher seu parceiro, seu emprego, sua vivência.

É necessário pensarmos a interseccionalidade, neste contexto, não como uma analítica que fragmenta ou para "superincluir" os sujeitos humanos. Pensar a analítica da interseccionalidade é possibilitar aberturas de sentidos sobre existências humanas singulares, que têm questões em comum, coletivas, sobre violências, opressões, e garantia dos direitos humanos, como também é compreender que é singular/ particular, pois existem as experiências e as vivências do modo de ser que é único.

A interseccionalidade é um conceito do problema que busca capturar as
consequências estruturais da interação entre dois ou mais isso eixos dá
subordinação. Ela trata especificamente da forma pela qual o racismo, o
patriarcalismo, a opressão de classe e outros sistemas discriminatórios criam
desigualdades básicas que estruturam as posições relativas de mulheres, raça,
etnia, classe e outros. (Crenschaw, p.177, 2002 apud Oliveira, p.87, 2020)

Segundo a perspectiva da análise Interseccionalidade, de Akotirene (2019), podemos compreender que as violências não são apenas sobre múltiplas formas e campos das identidades, 
TAVARES, Hiago de Souza; SOUZA, Marwyn Soares de. Travesti não entra: Uma análise crítica sobre o tratamento dado as travestis durante a Ditadura Civil Militar.

mas sobre uma forma de “(...) interação estrutural em seus efeitos políticos e legais” (Akotirene, 2019, p.63). Sendo assim, a interseccionalidade é necessária para perceber que mesmo as travestis que passam pela mesma violência ao burlar os papéis sociais de gênero, algumas ainda carregam consigo outras marcas, outros estigmas, como sua raça, sua orientação sexual, sua condição financeira.

É importante ressaltar que, nas leituras dos documentos da época citada, a travesti Rogéria é na maioria das vezes tratada pelo nome social, o nome escolhido. Além disso, sua arte aparenta ser respeitada, inclusive tendo divulgação de suas apresentações no jornal. É necessário, aqui, fazer um recorte de classe, pois Rogéria viveu a maior parte da ditadura militar fora do país, alcançando notoriedade na Europa. Em uma das páginas em que Rogéria aparece no título chamado definitivamente de mulher, o seguinte trecho: "Segura de si, Rogéria não gosta de complicação na maneira de se vestir nem das roupas emperiquitadas. (...) isso é coisa de travesti” (Vera Lúcia, 1973, p.2). No decorrer da leitura, há uma certa permissão à Rogéria de ser quem é, uma autorização seletiva, visto que a censura existia e interditou algumas peças teatrais e, ainda assim, Rogéria não sofreu, pelo menos de registro e descrito por ela, perseguição na época ditatorial do Brasil.

Com o título: "O sexo humilhado", o jornal Diário de Notícias relata a prisão de uma mulher de 40 anos confundida com travesti. O autor do artigo aponta que "Valéria e Rogéria são exemplos muito adequados para justificar eventuais equívocos. Mas partindo dessa premissa, chega a ser o cúmulo prender, como travesti, uma senhora de quarenta anos (...) é uma suprema humilhação à mulher" (Diário de Notícias, 1973, p.5). Além de normalizar o fato de ser permitido confundir uma mulher com a travesti Rogéria, o jornal aqui legitima a prisão de travestis, pois a preocupação do artigo foi a confusão de gêneros e não a prisão. As perseguições, sejam diretas, sejam subjetivas, eram identificadas no decorrer da análise dos fragmentos estudados do jornal Diário de Notícias. Com vários adjetivos pejorativos e amoladores de facas, as notícias do jornal marcam um período em que apenas existir era visto como motivo para repressões sexuais e outras formas de violação.

\section{Considerações finais}

Esse trabalho não tem a preocupação e nem intenção de abranger as possibilidades de análise e coanálise dos dados e jornais da época ditatorial. Contudo, tivemos a intenção de provocar os leitores e pesquisadores a identificar outras fontes e leituras sobre esse período de tantas revoltas e preocupações. 
TAVARES, Hiago de Souza; SOUZA, Marwyn Soares de. Travesti não entra: Uma análise crítica sobre o tratamento dado as travestis durante a Ditadura Civil Militar.

A violência com pessoas travestis, no período ditatorial, é ainda um campo aberto, com falta de estudos sobre a temática. Com isso, não é possível conclusões definitivas sobre o estudo. Cabe ao meio histórico e social a ampliação das pesquisas para uma maior compreensão das vivências de tais histórias de repressão.

Por fim, ler sobre o passado de pessoas travestis é também compreender o presente, pois atualmente a prostituição ainda é o único caminho para um público que sofre violências simbólicas e físicas durante a maior parte de sua vida. É necessária uma história crítica para que se possa mudar o presente e resgatar tais memórias com fins de reparação histórica e, claro, como uma forma de quebrar a forma binária de gênero que tanto represa as subjetividades. 
TAVARES, Hiago de Souza; SOUZA, Marwyn Soares de. Travesti não entra: Uma análise crítica sobre o tratamento dado as travestis durante a Ditadura Civil Militar.

\section{Referências bibliográficas}

AKOTIRENE, Carla. Interseccionalidade. São Paulo: Jandaíra; Pólen, 2019. Coleção Feminismos Plurais.

BAPTISTA, Luis Antonio. A atriz, o padre e a psicanalista - os amoladores de faca. In: BAPTISTA, Luis Antonio. A cidade dos sábios. São Paulo: Summus,1999.

DOMINGUES, Heron. Suicida-se travesti surrado no hotel e seviciado no xadrez. Diário de Notícias. Rio de Janeiro, 1972a.

DOMINGUES, Heron. Censura dá fim ao Les Girls que faz cartaz no Miguel Lemos. Diário de Notícias. Rio de Janeiro, 1972b.

DOMINGUES, Heron. Travesti Valéria operado do nariz: soco fez fraturas. Diário de Notícias. Rio de Janeiro, 1972c.

GAMBARRA, Gilvandro. Extremos: Elas corrompem menores e eles vão de travesti no “trottoir”. Diário de Notícias. Rio de Janeiro, 1970a.

GREEN, James N; QUINALHA, Renan (orgs.). Ditadura e homossexualidade: repressão, resistência e a busca pela verdade. São Carlos: EdUFSCar, 2014.

OLIVEIRA, Magg Rayara Gomes de. O diabo em forma de gente: (r) a existências de gays afeminados, viados e bichas pretas na educação. Salvador: Devires, 2020.

QUINALHA, Renan Honório. Contra a moral e os bons costumes: A política sexual da ditadura brasileira (1964-1988). São Paulo: USP, 2017.

RIZZO, Walter. Travesti não entra. Diário de Notícias. Rio de Janeiro, 1970.

SILVA, Edlene Oliveira; BRITO, Alexandre Magno Maciel Costa. Travestis e transexuais no jornal Lampião da Esquina durante a ditadura militar (1978-1981). Dimensões, v. 38, p. 214239, jan-jun 2017. Disponível em :< http://periodicos.ufes.br/dimensoes/article/view/16813>. 
TAVARES, Hiago de Souza; SOUZA, Marwyn Soares de. Travesti não entra: Uma análise crítica sobre o tratamento dado as travestis durante a Ditadura Civil Militar.

Acesso em: 4 fev 2021.

SILVEIRA, Joel. São 50 "bonecas” e vieram pra sambar. Diário de Notícias. Rio de Janeiro, 1970.

TAVARES, Hiago de Souza. Travesti não entra: uma breve análise do tratamento dispensado às travestis no período da ditadura militar. Trabalho Final de Curso (Licenciatura em Ciências Sociais) - Universidade Federal Fluminense, Instituto de Ciências da Sociedade e Desenvolvimento Regional, Campos dos Goytacazes, 2018.

VERA LÚCIA. Rogéria definitivamente mulher. Diário de Notícias. Rio de Janeiro, 1973. 